Carolyn M. Brooks, Jennifer Poudrier

University of Saskatchewan, Canada https://doi.org/10.18778/1733-8077.10.4.02

\title{
Anti-Oppressive Visual Methodologies: Critical Appraisal of Cross-Cultural Research Design ${ }^{1}$
}

Abstract The purpose of this article is to draw critical attention to the use of photovoice as an anti-oppressive method in research with Aboriginal peoples. In response to the historical vulnerability of Aboriginal peoples to research that "wants to know and define the Other," anti-oppressive methods deconstruct taken-for-granted research models and focus on privileging Indigenous voices, political integrity, and justice strategies. Anti-oppressive approaches are connected to emancipation and cannot be divorced from the history of racism. Theoretically, photovoice aligns well with anti-oppressive goals, using photographs and storytelling as a catalyst for identifying community issues towards informed solutions. Having roots in Freireian-based processes, photovoice has the goal of engaging citizens in critical dialogues and moving people to social action. Drawing on our recently completed photovoice study, Visualizing Breast Cancer: Exploring Aboriginal Women's Experiences (VBC), we demonstrate that photovoice seems successful in enhancing critical consciousness among participants, but that outcomes may not be disruptive. While photovoice has the potential to develop counter-hegemonic anti-oppressive knowledge, this may be lost depending on how the research process is encountered; thus, we propose the implementation of a revisionary model which incorporates a culturally safe anti-oppressive lens.

Keywords Photovoice; Cross-Cultural Research; Visual Methods; Anti-Oppressive; Indigenous Research

Carolyn M. Brooks is an Assistant Professor of Sociology in the Department of Sociology at the University of Saskatchewan, Canada. Her research and publications are primarily focused on Aboriginal women's health, visual and community based participatory methods, crime prevention, youth resilience, and the politics of punishment. She teaches courses in Aboriginal Justice, Criminology, and Social Control.

email address: Carolyn.Brooks@usask.ca
Jennifer Poudrier is an Associate Professor in the Department of Sociology at the University of Saskatchewan. She is a Metis researcher whose work primarily focuses on community based participatory research with First Nations communities on the topics of breast cancer, women's health and body image, youth and resiliency. New research areas emerging from her community based partnerships are on boys, men, and masculinities in First Nations communities.

email address: Jennifer.Poudrier@usask.ca
$\mathrm{T}$ he use of photovoice while working with Aboriginal ${ }^{2}$ peoples and communities is emerging in a number of contexts (e.g., see: Moffit and Robinson Vollman 2004; Poudrier and Kennedy 2007; Adams et al. 2012). Photovoice, which was designed as a strategy for health promotion (Wang and Burris 1997; Wang, Cash, and Powers 2000), aims to shift power dynamics through empowering community introspection towards enhanced citizen engagement and social change (Wang and Burris 1997; Wang 2003; Kubicek et al. 2012; Freedman et al. 2014). In response to problems with the historical vulnerability of Aboriginal people to scientific research that "wants to know and define the Other" (Tuhiwai Smith 2005:86), anti-oppressive research deconstructs taken-for-granted ways of doing research, from the choice of research methods, through data collection and analysis, to dissemination. Key principles of anti-oppressive methods are finding solutions together in researcher/participant partnerships, political integrity, and critical dialogue on racism and different forms of oppression. Anti-oppressive researchers (inclusive of anti-racist, postcolonial feminists, critical race feminists, black feminists, and more) place marginalized peoples at the center, challenging complacency and assisting in the development of counter-hegemonic discourse, and providing a basis for unifying political activity (Hill Collins 1998; Razack 1998; Moo-

This research was made possible by a number of research grants and funding organizations, including: Canadian Breast Research Council of Canada Doctoral Fellowship, and the Saskatchewan Health Region.

${ }^{2}$ The term Aboriginal is intended to be inclusive to all of the women whose stories frame these pages. The term Aboriginal peoples refers collectively to Metis, Inuit, and First Nations, and follows terminology used by the Royal Commission on Aboriginal peoples (Waldram, Herring, and Kue Young 2006:xi).
sa-Mitha 2005). Drawing on our recently completed photovoice project, Visualizing Breast Cancer: Exploring Aboriginal Women's Experiences (VBC), we critically examine the potential of photovoice as an anti-oppressive approach to engaging in health research with Aboriginal peoples. In particular, we explore and discuss the extent to which visual methods, and specifically photovoice, can be redesigned to fit within an anti-oppressive framework suitable to research with Aboriginal women.

The history of colonization is important when gathering health data about Aboriginal peoples, and has led many communities to be "deeply suspicious" with respect to how data about Aboriginal populations are used (Marrett, Jones, and Wishart 2004:13). As Linda Tuhiwai Smith (2005:87) writes, "the history of research from many Indigenous perspectives is so deeply embedded in colonization that it has been regarded as a tool only of colonization and not as a potential tool for self-determination and development." Moreover, the use of visual images and photographs of Aboriginal peoples and communities have been the subject of great concern since they have often represented Aboriginal people from a colonial lens, effectively reproducing problematic stereotypes about who Aboriginal people are. In response to the problems of "Othering" and research vulnerabilities (Tuhiwai Smith 2005:86), anti-oppressive research approaches are connected to emancipation and cannot be divorced from the history of racism and other forms of oppression. Rigney (1999) defines three principles of Indigenist research (an anti-oppressive approach): privileging Indigenous voices, political integrity, and resistance. Redefining research is also about 
rebuilding governance, restoring culture, and enhancing community. Anti-oppressive theories and research, more generally, understand the intersectionality of oppressions, the importance of difference, heterogeneity, subjectivity, situated telling, and multiple voices (Moosa-Mitha 2005). Anti-oppressive approaches and Indigenous methods focus on reintroducing the voices and experiences of more marginalized or oppressed peoples towards social justice and the creation of justice strategies (Wing 2003).

In principle, photovoice seems to align well with anti-oppressive goals. Informed by feminist epistemology, literature in visual knowledge and power, and based on the theoretical work of Paulo Freire (1970), this method aims to shift power dynamics through communal introspection (Burke and Evans 2011; Adams et al. 2012; Kubicek et al. 2012; Lai, Jarus, and Suto 2012; Freedman et al. 2014). Photovoice is intended to facilitate a deepened level of critical consciousness amongst participants (Carlson, Engebretson, and Chamberlain 2006; Burke and Evans 2011), which is the impetus for realizing connections between personal and social issues, as well as enhancing collective responsibilities and community members' sociological imaginations. Considerable interest has been expressed with respect to the use of visual methods, especially photovoice and other arts-based methods, in research with Aboriginal populations (Poudrier and Kennedy 2007; Castleden and Garvin 2008; Adams et al. 2012). Declared benefits include the balancing of power between research participants and researchers, generating a historical visual record over generations (Adams et al. 2012), as well as building capacity, skills, and appreciation of cultural choices (Castleden and Garvin 2008). Visual ethnography enriches textual and interview data by furthering the reconstruction of participant experiences (Konecki 2009). Less discussed are the anti-oppressive goals of visual methods, including the development of critical consciousness and development of counter-hegemonic justice strategies. Our purpose here is not to provide an exhaustive overview of the VBC research findings, but rather to explore themes arising about the anti-oppressive potential of visual methods.

The context for this discussion is provided through an overview of anti-oppressive theory and photovoice research. We then introduce the VBC research project and relevant findings, illustrating the potential and limitations of the photovoice method, as well as the risk that the visual images may continue to represent Aboriginal peoples from a colonial lens, reifying mainstream culturalized images. Our findings suggest that while photovoice has the potential to develop counter-hegemonic anti-oppressive knowledge, this may be lost depending on how the research process is encountered; thus, we propose the implementation of a revisionary model which incorporates a culturally safe anti-oppressive lens. The cultural safety lens simultaneously views individuals in their location, related to colonial marginalization (Browne and Fiske 2001; Anderson et al. 2003), moving beyond cultural sensitivity to an analysis of power imbalances. We suggest that photovoice methods are not anti-oppressive implicitly; rather, they are dependent upon the ethics and practices of researchers, participants, stakeholders, and policy makers.

\section{Anti-Oppressive Theory and Photovoice}

Anti-racism (Okolie 2005), critical race feminism (Wing 2003), postcolonial Indigenous, and feminist theories (Anderson 2000; 2004; Browne, Smye, and Varcoe 2007) represent anti-oppressive theories (Moosa-Mitha 2005) and give rise to specific questions relevant for Aboriginal women's health concerns. By situating marginalized peoples voices at the center, anti-oppressive researchers provide a lens to understand how gender, racialization, class, and historical positioning shape their voices, experiences, and communities. With similarly stated objectives, photovoice aims to shift power dynamics through privileging community introspection, while inspiring critical consciousness towards addressing substantive issues at the community and structural levels (Wang 2003).

Originally, anti-oppressive theories brought in the notion of intersectionality of oppressions (Hill Collins 1998; Razack 1998). Authors such as Hooks (1989; 1990) and Hill Collins (1998) argued that we cannot single out, for example, racial domination because oppressions are interrelated. Anti-oppressive theories saw the elimination of all injustices as part of their emancipatory aims. In addition, identity is acknowledged as fluid and changing, not essential. The recognition of difference is important, along with acknowledgment of the dialectical relationships with relational, cultural, and structural factions. The anti-oppressive framework deconstructs the dichotomy of oppressed and oppressor, recognizing that people can speak from both locations simultaneously, as well as acknowledging the power found within the margins (Razack 1998).
Anti-oppressive theories emphasize the importance of agency and subjectivity. Beginning with the standpoint of the oppressed and hearing the voices that have traditionally been lost is essential, especially within enlightenment thinking (which spoke of the Other). Anti-oppressive theories recognize the difference between people's experiences and the similarities in the experience of communities. Patricia Hill Collins (1998; 2007), for example, brings forward voices and experiences of African American women, recognizing differences of experiences and similarities in collective struggles of communities: "the heavy concentration of U.S. Black women in domestic work coupled with racial segregation in housing and schools meant that U.S. Black women had common organizational networks that enabled them to share experiences and construct a collective body of wisdom" (2007:347-348). She realizes that African American women share certain discriminatory experiences regarding housing, employment, and being watched in everyday living experiences. In addition, although racism is more difficult to talk about in a context of colorblindness (Hill Collins 2012) or multicultural policies (Schneider 2008), these shifts are said to reproduce racial disparities through concealing differences (Hill Collins 2012) or legislating Otherness (Schneider 2008) under the guise of inclusiveness. "Multiculturalism has been attacked for offering a policy of containment, a policy which, by legislating Otherness, attempts to control its diverse representations, to preserve the long-standing racial and ethnic hierarchies in Canada" (Kamboureli 1996:11-12 as cited in Schneider 2008). Darias-Beaute11 (2000) argues that multiculturalist concepts of ethnicity refer to Othering others, while "white Canadians" are not categorized. Colorblind and 
multicultural policies are criticized for leaving unaddressed the structural racial inequalities, which continue to persist (Hill Collins 2012)

Anti-oppressive theories aim to facilitate resistance through increased understanding of the intersecting and shifting forms of oppression (Moosa-Mitha 2005). The aim from this perspective is to understand multiple historical and current forms of oppression by reclaiming voices of experience. Anti-oppressive research must be critical and disruptive, and designed with an idea of the shortand long-term benefits for research participants, be they individual, social, cultural, and/or political (Moosa-Mitha 2005)

In theory, photovoice aligns well with the described anti-oppressive goals, using photographs and storytelling as a catalyst for identifying community issues and critically reflecting on these issues towards informed solutions (Wang 2003; Adams et al. 2012; Kubicek et al. 2012). Having roots in Freireian-based processes (Freire 1970; 1973), photovoice has the goal of engaging citizens in critical dialogues and moving people to social action (Carlson, Engebretson, and Chamberlain 2006; Kubicek et al. 2012). Although implicit in the photovoice construct, the outcome of social action and community change is not as frequently discussed. Photovoice brings forth the voices of the participants and communities, often sharing insights never heard before (Wang and Redwood-Jones 2001; Wang 2003; Chonody et al. 2013). However, what is discussed less are the developments of counter-hegemonic strategies and whether these outcomes fit with anti-oppressive objectives.

\section{Background and Methodology}

The VBC research was undertaken in reaction to the prevalence of breast cancer and the calls for more research into the effect of race on cancer care and cancer experience (Gill and Feinstein 1994; Leedham and Ganz 1999). Funded by the Canadian Breast Cancer Research Alliance (CBCRA), this was the first photovoice project used to understand the meaning of breast cancer for Aboriginal women. A key theme resulting from the research was the intersection of multiple marginalizations (e.g., geography, gender, race, class) and how this bears on the needs and experiences of Aboriginal women. This research contributed to growing the knowledge of the link between social justice and health inequalities, as well as to a critical appraisal of cross-cultural research. Working alongside $12 \mathrm{Ab}$ original survivors of breast cancer, we collected over 200 photographs and 28 interview transcripts. We recruited the VBC participants from First $\mathrm{Na}-$ tions News papers, breast cancer support groups, and through posters at Aboriginal agencies and cancer centers. We were honored to have Aboriginal breast cancer survivors from Saskatchewan share their stories with us through photography, one-on-one interviews, as well as focus groups and sharing circles. None of the women knew each other before participating in this study and many said they had always wanted to meet another Aboriginal woman who had the experience of breast cancer. Feeling impassioned by their newly formed relationships and the importance of their combined stories, all of the women requested to use their full identities, using their own names and photographs. We modified ethics accordingly.
The initial focus group was an opportunity for each of the women to share their story of breast cancer, be provided with a digital camera, and be invited to take pictures of their experience of breast cancer. Later, the women were asked to select photographs they had taken, and which were particularly meaningful, and discuss them in-depth in a one-on-one personal interview. The women were invited to take more pictures after individual interviews and focus groups towards individual realization of data saturation; indeed, some women had their camera for more than six months. The data collection in our study was continuous and the ongoing relationship building was an unexpected privilege.

The final two stages of the research involved a sharing circle for the women and a community workshop where the women shared their stories and pictures with community breast cancer stakeholders and community policy makers. To ensure that participants in our project were offered an opportunity to meet with relevant policy makers, connections were made with the relevant Health Regions, Breast Health Centers, Breast Cancer Action networks, Breast Cancer Community of Stakeholders, and Indigenous Peoples Health Research Centers. All of these agencies in Saskatchewan had expressed an interest in the findings of this research and in services that may better meet the needs of the Aboriginal women breast cancer survivors. Three outcomes of the community event were immediately evident. First, relationships were established between Aboriginal breast cancer survivors and interested community members. Second, findings were shared with community groups, which built capacity and raised awareness in the area of Aboriginal women's experiences with breast cancer. Third, developments related to support, fundraising, and policy work were initiated.

Through this research, the participants, researchers, and community partners participated (in a self-reflexive way) to create a new understanding of Aboriginal women survivors' lives through collaboration. Given the incredible diversity in the background and experience of Aboriginal women across Canada and Saskatchewan, we did not pretend to offer an Aboriginal woman's perspective from the findings. We fully recognize that no such exclusive perspective can exist.

Through listening to their stories, we learned that these women shared diverse experiences of fear, fear of recurrence, isolation, problems with social support, shifting identities, pain, early menopause, body satisfaction and dissatisfaction, well-being, confusion, wisdom, laughter, strength, resilience, and hope. The narratives the women spend the most time developing are the ways that their stories shift by the interrelated influence of gender race, class, history, and geographical space, and how these social forces shaped and limited the resources and survival strategies available to them. Following the anti-oppressive model, it is important that these women's stories be situated and understood in this context. The women's stories revealed some commonalities related to colonial histories, racism, and other experiences, yet they also reveal incredible diversities. The complexity of the women's experiences points to the importance of 
employing methodologies that can fully appreciate complex intersecting of social forces and multiple agencies. The question is whether photovoice provides these tools and can be defined as anti-oppressive.

\section{Findings}

Three key themes emerged relating to the anti-oppressive potential of photovoice. First, participants benefitted from the photovoice project on individual, relational, and community levels. Second, photovoice provides multiple opportunities for deepening layers of participant-led analysis and uncovers multiple social forces that affect participant experiences with breast cancer. This second finding is most important here, demonstrating that the photovoice method promotes, or at least enhances, critical consciousness through the act of photography. Through their photography, the participants linked personal problems to larger sociological concerns. Third, the participants expressed fear that their lives would be misinterpreted, analyzed here as a fear of Othering and culturalism. Overall, the findings suggest that photovoice research has the potential to be anti-oppressive, developing counter-hegemonic knowledge informed by voices typically marginalized or not heard. However, we argue that this potential may be lost, depending on how these images and the research is used and seen by others. Informed by the findings from insights of the VBC participants, this work supports a revised photovoice model and warns against culturalized reproductions of photovoice research with Aboriginal people. Our findings argue that photovoice researchers must consciously situate themselves within an anti-oppressive framework. Our recommendation is a conscious application of a lens defined as "culturally safe" at each stage of the research process, including the photovoice data collection process and dissemination. We suggest that photovoice methods are not anti-oppressive implicitly; rather, they are dependent upon the ethics and practices of researchers, participants, stakeholders, and policy makers.

\section{Individual, Relational, and Community Benefits}

A goal of photovoice and a key component of research with Aboriginal peoples is for participants to benefit individually, socially, and politically from their involvement. Although some of the women participants at first expressed doubts about the picture taking process and did not immediately see the intuitive sense in setting them loose with a camera, over time all of them saw the exercise as beneficial. For example, two of the women expressed uncertainty about what was expected from them. Sandra said: “I wasn't sure what I was going to take pictures of...how to capture life." A number of women shared concerns that they could not take pictures of natural medicines, Sweat Lodges, Sun Dance, or other ceremonies because they are sacred. Dorothy, for example, talked about wanting to take pictures of the medicine that she used to heal, but said she could not take these pictures because then the medicine would no longer work-its healing qualities would be given away. She feared that if she took a picture of natural medicines or ceremonies, they may no longer have healing properties. Despite initial fears and hesitation, the women found creative ways to present spirituality and traditional medicines, and they all reflected on the importance and enjoyment within the photovoice process. Shelley, for example, remarked on the personal reflection the camera allowed: "This was a wonderful, wonderful exercise...it was a powerful exercise, I really liked it." The participants also saw the potential of photovoice research to assist them to work together towards helping other Aboriginal women breast cancer survivors, making comments such as: "I pictured right away that it would help others" (Marion) or "I want to bring these pictures back to my community to show other Aboriginal women that they do not have to be so afraid of cancer" (Dorothy). Regarding the benefits of the research on an individual relational, and political level, Tina said:

I need to tell you three [research team] that you do not know how much you have helped me... I didn't know these ladies before. I only knew other non-native breast cancer survivors and I felt very alone and I will be forever thankful. I hear Marion's story and I hear myself. I hear all the other ladies that we haven't touched yet are longing for us as well.

As researchers, we learned the importance of listening to what the women needed in the research process. Picture taking was a personal journey and this could not be rushed. This meant that our own research timelines were modified, ethics amended, and data collection coincided with relationship building. We were reminded of the importance in qualitative research for researchers to be learners and listeners, not experts.

\section{Multiple Opportunities for Critical}

\section{Consciousness}

Photovoice is said to be a tool to develop further critical consciousness among participants, moving citizens to participate in social change and policy (Carlson, Engebretson, and Chamberlain 2006). Findings here suggest that photovoice provides multiple opportunities for expression of diversity, as well as layers of critical consciousness, especially through photography, interviews, and sharing circles. The women demonstrated critical consciousness through the photovoice process, realizing shared struggles and concerns relating to cancer survivorship and being an Aboriginal woman.

The women in the VBC research talked about their shared experiences of racism. For example, Sandra talked about continued racism throughout her life and how this affected the trust she felt towards others, as well as the impact on her own identity: "Growing up as, as an Aboriginal woman in [name of the city], I mean, there's very, dealing with the racism and stuff like...that's something that was part of my everyday life." Racism and fighting against racism are also [quite strikingly] expressed through their photography, symbolically as "fighting against it," and through imagery of treatment and experience. Describing the picture below, Sandra spoke about her grandson, seen doing a karate step out of the box, symbolic to her of a brighter future, fighting against and being free from racism: "So, you know, my future is looking brighter...you know that, that we're gonna break away from all of these horrible things... Racism... and he's gonna make it better." 
Figure 1. Breaking away from racism. ${ }^{3}$

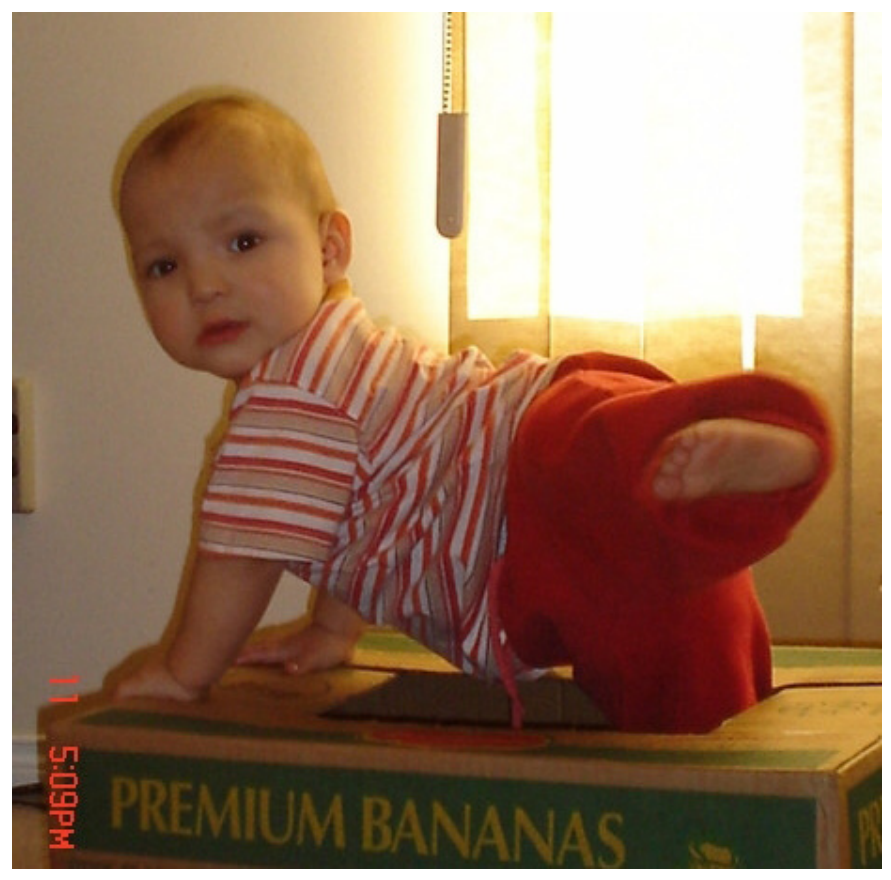

Margaret and Marjorie talked about the intergenerational impact of residential schools, the loss of culture, and what this has meant for their own health, as well as the well-being of others. As Margaret explains, "I've been an urban Indian for thirty five years in [name of the city]...people with Masters, with PhD's...they have lost their identity...and parents have lost their parenting skills...and ours go back to years ago from uh....residential school survivors." Marjorie talked about how violence against her at the residential school contributed to her resiliency and strength to be able to overcome and fight against her cancer:

In boarding school, they could say: oh, you're this, you're that, you stupid, whatever...like what you tried

3 Photographs included in this article are reproduced with
permission from research participants in the study entitled: Visualizing Breast Cancer: Exploring Aboriginal Women's Experiences. to beat down in me, you brought something up that's been hidden right along and brought it up and I'm a better person for it.

Other participants interpreted behaviors such as silence and anger, said to be typical of Aboriginal women, as also linked to historical oppression. The women spoke of the silencing of many Aboriginal women (on and off reserve) over time, linking this to historical assimilation, residential schools, day schools, histories of violence, and continued racism. Marjorie, for example, captures an intergenerational analysis when she spoke about women being unwilling to do self-examinations or to even talk about cancer. She explained:

With us there has been so much intergenerational damage...everything is very hush hush...we need to tell [each other] it is ok to take your shirt off and bra off-so what if you are lop sided, you are alive...but, we have been hushed...that's how I view myself-the package is a little scuffed up...but, I am here...I am alive.

Marion spoke of her own experience and how silence was learned in her childhood at residentia day schools. Day schools were government funded, church-run residential schools, but the children lived in boarding houses, orphanages, hostels, and convents rather than the dormitories used in residential schools:

I wasn't in residential school, I was in day school but the teachers were totally mean and I learned to be silent. Because I used to always get hit...I was just afraid...then I realized I couldn't ask anybody to go through cancer for me. I had to do it myself. That was the hardest thing for me, staying strong.

As is outlined in much of the literature on racism and health (Nazroo and Williams 2006), the women's stories and visuality pointed to structural and institutional racism, which they indicated played a role in economic and social disadvantage; this can be viewed as centrally connected to their health, well-being, and experience of breast cancer.

The VBC women also identified sociological and environmental concerns, including problems with on-reserve housing, water quality, accessibility of health care and medical taxi services in rural areas, as well as socio-economic and financial issues related to health inequalities. For example, the VBC participants demonstrated ways in which resources and health strategies available to them were circumscribed by histories, race, class, and gender through the photographs. One example of connections between personal experiential accounts and social forces affecting their lives is captured by Sandra in her picture; praying at work. In this picture, Sandra not only reflects on her own socio-economic concerns but she relates this to concerns of Aboriginal women in general. She explains,

that was me on my knees at work. Just kind of praying. Lord please let me keep my job so I can feed my children...a lot of Aboriginal women have raised their children by themselves or run the home by themselves...if you are all that family has, then you're holding up a lot of people and you can't afford to be sick.
Figure 2. Praying at work.

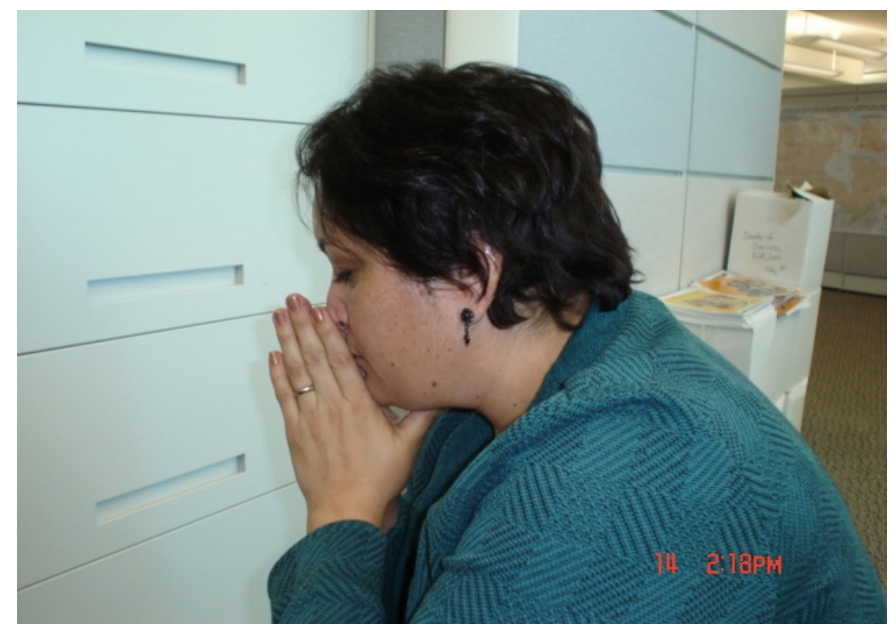

Dorothy's picture of her housing on-reserve also portrays a strong critical analysis of societal inequality. Dorothy said she moved into the city during treatments because of poor living conditions on-reserve. Through her picture, she described the housing and her environment. She talked about the wood stove in the picture, which is her only source of heat for cold Saskatchewan winters: "...that's my heat for winter time... a wood [stove]..."

Figure 3. Living on my reserve.

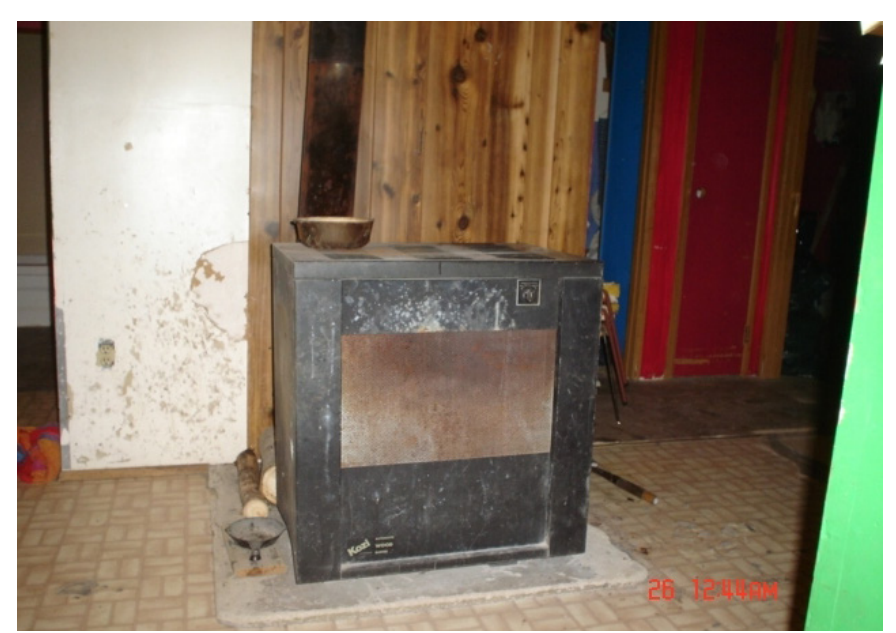

Cheryl talked about food availability, crisis in communities, and violence: 
I think programs and things when they're dealing with Aboriginal people, they need to be realistic and look at the issues that are really facing them, you know the stuff, like whether its poverty or abusive relationships or FAS or, you know, there is all of these other things that can come in that, they're very prevalent in First Nations Society...I mean, you can't tell somebody who lives up in like...[where it costs] like twelve dollars for milk or...like how do you tell these women to eat properly.

All of the women described issues related to isolating conditions, poverty, family crises, and problems with alcohol, which were viewed as hindering their ability to seek medical information or attention and causing deeper distress. The key point here is that the women were moved to reflect on the broader context of their lives and the lives of others in their community through the process of taking and sharing their pictures. The women said that having the camera for a period of time (some up to six months) allowed them to think beyond their own experience to what other Aboriginal women may also be experiencing and what they would like to see change for women who experience future breast cancer diagnoses. Both the women and the researchers were amazed at the creativity and the potential for the women to express other social forces and realities, such as racism, spirituality, and environmental issues, through photography.

\section{Othering and Culturalism}

Arising from the research were not only Aboriginal women's experiences of breast cancer but also warnings from participants of practices of Othering and culturalism. These processes mean that stereotypical and often racialized assumptions of identity, culture, and difference are placed onto certain groups which are not reflective of actual identities (Browne, Smye, and Varcoe 2007).

The VBC women shared stories of their own discrimination within the health care system and support services, noting that visual images and information about breast cancer were often directed at middle class white women. They saw the production of their own visual images and stories of survival through participation in the photovoice project as being important for health care professionals/advocates, as well as other Aboriginal women with breast cancer; to know they were not alone and to identify ways of getting more information and support. What is most important here is that the women shared fears about the misuse of the pictures and how their lives may be viewed and (mis)understood. Embedded in a history where visual images of Aboriginal peoples have reproduced colonial stereotypes (Tuhiwai Smith 2005), our findings reveal the women's continued fear of culturalist understandings of their visual images and storytelling. Although not an exhausted list, the women expressed concerns that the pictures may lead to further Othering and stereotyping of: Indigenous cultures and healing methods, personal identities and expressions, and social problems.

Although Aboriginal people are more common ly using both modern and traditional methods towards healing, mainstream perceptions about
Indigenous healing and culture often continue to reflect colonizing attitudes (Robbins and Dewar 2011). The women spoke of traditional Indigenous approaches to healing and their fears about how this practice is perceived.

Although many of the women used traditional medicine to heal, many hid these practices from their doctors, support workers, nurses, and social workers. For example, many of the VBC participants talked about the importance of First Nations spirituality in healing, shown, for example, in their pictures of rocks, a drum, a sash, and colors.

Figure 4. Spirituality.

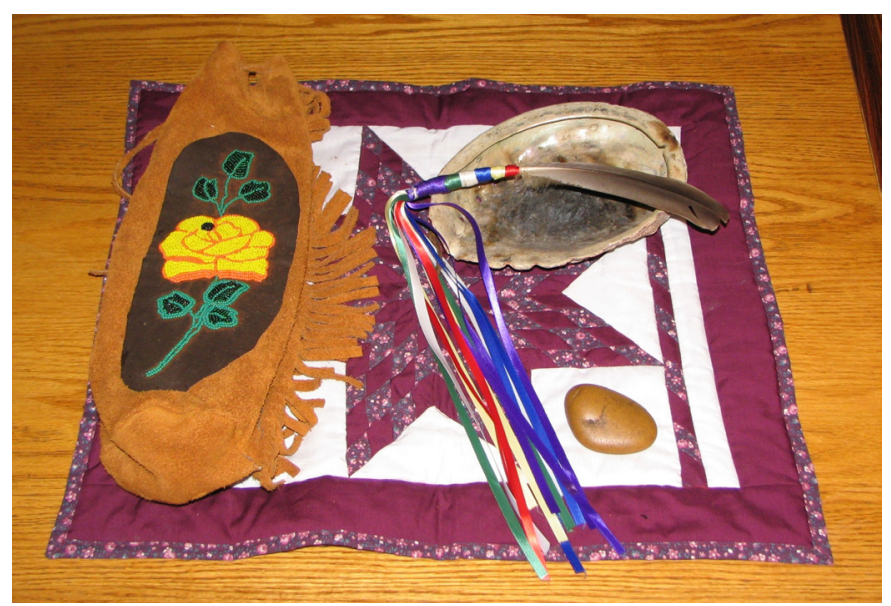

Mary said that "...traditional friends and the ceremonies and healing medicines helped [her] heal emotionally, mentally, spiritually, and physically." However, the women also feared that their behaviors, which they defined as outside of the mainstream mentality, would be judged. As a result, these women hid an important part of themselves. Similarly, although the women wanted to share the importance of traditional practices visually with other Aboriginal women survivors in the VBC photovoice project, they feared that this may be misunderstood unless understood in the context of
Indigenous knowledge systems, culture, and history This is upheld in the literature on traditional medicine. Frideres (1994; 2009), for example, argues that many Aboriginal patients may heal themselves and not follow specific medical orders and, as a result, risk being labeled "irresponsible" or "incapable."

Acknowledging the importance of sharing cultural images and themes, Sandra expressed her fear that all of the participants would be viewed with the same cultural lens. Sharing her own picture of "Indian art," she noted that "We are not all beads and feathers."

Figure 5. "We are not all beads and feathers."

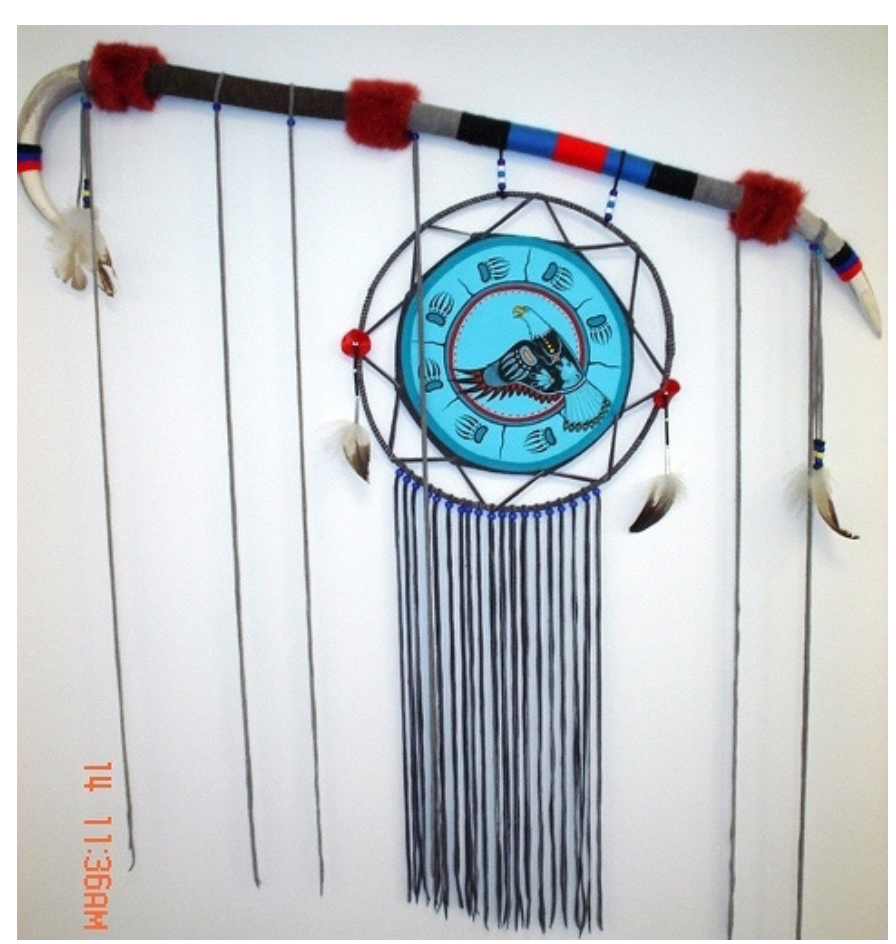

Sandra said that she used this visual image not to celebrate her culture (which she also wanted to do), but rather to represent how traditional culture and Aboriginal identity has shifted from an authentic identity to a performance. For example, she said: 
This is our spirituality and...some people will just perform for you, for white people...cause that's what you do, you put your, your regalia on. You know, there was a time for spiritual dances and for things like that, now it's more of an entertainment thing for others.

Her picture of masks symbolized her struggle to make "other people feel comfortable," as well as the larger Indigenous struggle of inauthentic identity. Speaking to issues of racial identity, as well as cancer experience, she said: "I wear masks to make other people more comfortable."

Figure 6. Masks.

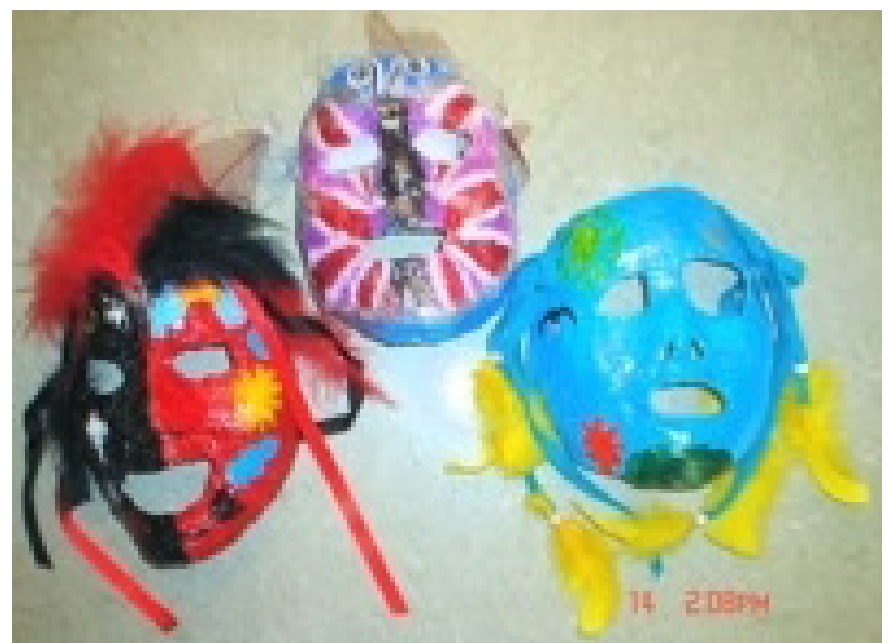

Although the women wanted to have their Aboriginal identity and continued effects of colonization acknowledged, they feared that this would be used to solely define all of their experiences. Sandra identifies the importance of realizing multifaceted identities in the following picture, by visually depicting her fear of being misrepresented, yet pride in standing inside a traditional tipi, as well as in front of her modern university.
Figure 7. Multifaceted identities.

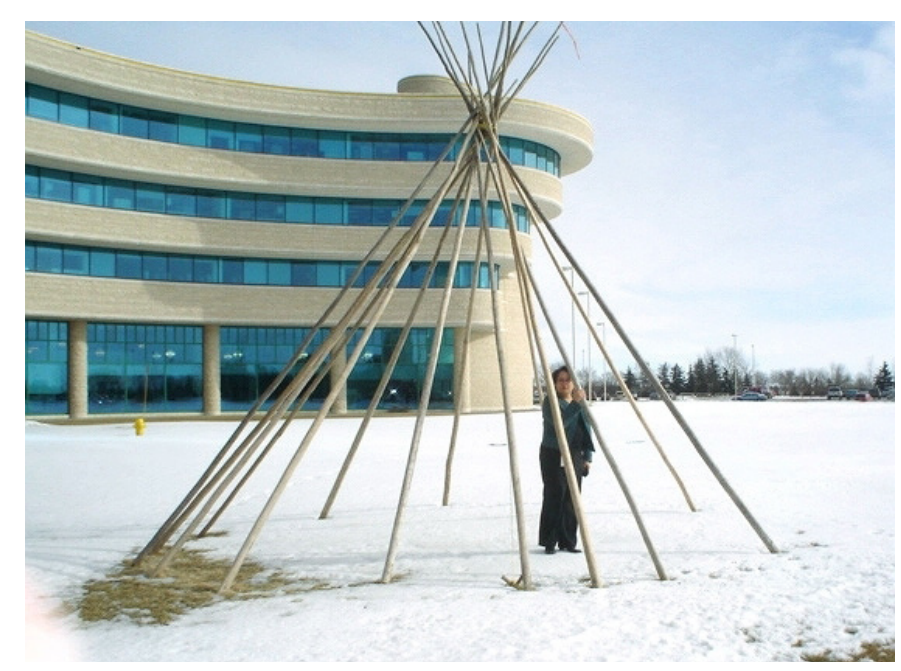

Sandra described a number of things about this picture. This picture embodies her current pride in $\mathrm{Ab}$ original women's successes and embraces tradition, yet the bare skins of the tipi were said to represent her fear-of both cancer, as well as continued racism based on her "Indian" identity. She talked about the skins missing on the tipi, which she told us is symbolic of her being exposed, and the university where she received her degree. She said that she was trying to hide and explains that:

..you can very much see that I am an Indian. This one... is a tipi. It's a skeleton, the skins are missing, so I'm exposed is what I'm saying...you see the past...and the present. That's me inside of there, you know. I'm trying to hide, but I'm not hiding...you can very much see. You can see that I'm an Indian, for me, I can see that, you know. This is where I went to university, too. That's where I got my degree.

We suggest that the pictures of masks, spirituality, and multifaceted identity not only provide descriptions of the women's cancer and life experience but are powerful examples of the fear of Othering and culturalism.

As described above, the women shared their experiences of anger, silence, poverty, homelessness, and conditions on-reserves. They also spoke about being survivors of intimate partner violence, childhood abuse, and/or residential school violence. Some of the women said that these experiences contributed to their silence about breast cancer and violence, but many also indicated this contributed to their resilience and strength to overcome and fight cancer. Their words are powerful and humbling. For example, Cheryl said: "I've been 25 years with an abusive husband verbally...so I guess that I had to be strong. If I could live through that, I thought that chemo would be easy." Sandra similarly shares: "cancer rocked my soul like my husband did-beat me-and cancer did the same, it beat me."

The VBC women shared their stories of struggle in multifaceted contexts, representative of political,

economic, and historical realities. They did not want their stories and pictures to represent them as being more different than other women experiencing breast cancer, but they also did not want to miss sharing their worst stories symbolic of Aboriginal peoples' struggles more generally.

\section{Discussion}

The findings suggest that photovoice research has the potential to be anti-oppressive, developing counter-hegemonic knowledge informed by voices typically marginalized or not heard. They also help to inform a revised model of photovoice research, which includes a conscious application of a "culturally safe" lens at each stage of the research process, including (and especially at) dissemination:

Table 1. Model of Photovoice Process, Culturally Safe Lens, and Anti-Oppressive Outcomes.

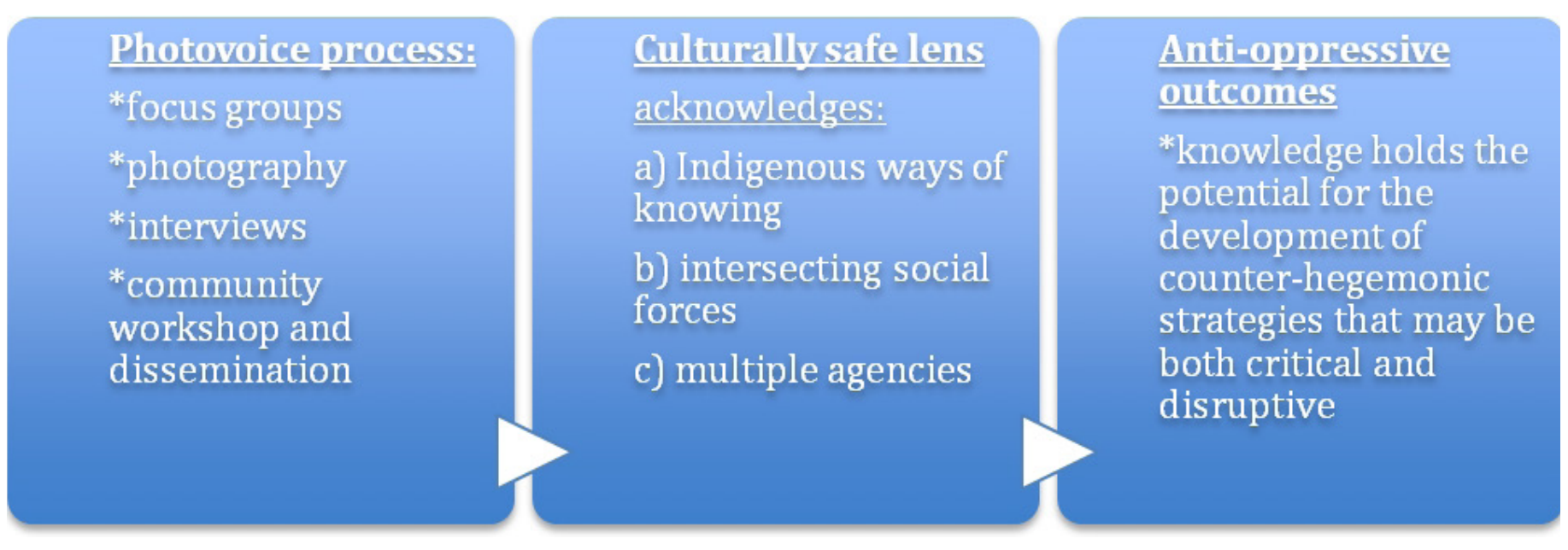

Source: self-elaboration.

Cultural safety is a lens which simultaneously views individuals in their location related to colonial mar- ginalization (Wood and Schwass 1993). The idea of cultural safety is that researchers, policy makers, and 
health care workers ensure the effect of history, especially colonization is understood when addressing Aboriginal women's health concerns (Browne and Fiske 2001). This does not mean simply being sensitive to cultural differences or specific needs, but acknowledging inequalities and the effects of colonization and neo-colonialism: "[c]ultural safety moves beyond notions of cultural sensitivity to an analysis of power imbalances, institutional discrimination, and the nature of the relationships between the colonized and colonizers as they apply to health care interactions at the macro and micro levels" (Browne and Fiske 2001:8-9). Applying the lens of anti-oppressive theory to cultural safety draws attention to social positioning within historical and social changes.

A lens of cultural safety helps unravel the complex ways in which the women have had their rights respected or have been disempowered and how this treatment has affected their health and well-being. This same lens may therefore reveal "taken for granted processes and practices that continue to marginalize Aboriginal voices and needs" (Anderson et al. 2003:199). This lens points to cultural histories, identities, and social problems being subordinated through processes of culturalization and Othering. As such, applying cultural safety to the process and dissemination of photovoice findings helps ensure these taken-for-granted practices, which may contribute to the furthering of marginalization viewed differently-towards a counter-hegemonic discourse, which will influence health care practice informed by a different world view.

The culturally safe anti-oppressive lens ensures that the development of knowledge begins with Indig- enous peoples' perspectives, deconstructing social constructions of identity, culture, and Othering This perspective warns against assumptions about class, cultural, and racialized identities, which often inform medicine and mainstream theories of "risk" for ill health and social problems. The cultural safety lens identifies the wider determinants of health evident in the intersection of class, culture, racialization, historical subjugation, and gender, and ensures the visual images do not blame individual women and/or entire groups of people/cultures for lifestyles associated with ill health

When applied to the process of photovoice, this culturally safe lens helps to ensure the respectful and dialectical development of critical consciousness. Part of this is ensuring that the Indigenous knowledge is respected through the use of what Castleden and Garvin (2008:1401) define as a "feedback loop," "seeking input from the entire community at regular intervals" on the research process and dissemination. It was reinforced in the VBC research that photovoice with Aboriginal peoples demands a prolonged immersion in the research process in order to build rapport and trust, as well as support the developmen of relationships among the women themselves with the community stakeholders and researchers.

Through encouraging the women to keep the camera for the time they need and ensuring a feedback loop (Castleden and Garvin 2008), the analysis of photographs became intersubjective and layered in meanings. Following this lens, visual images were examined for their individual meaning, their social and cultural contexts, and the women's interpretation of what lies both internally and beyond the image. His- torically, sociological interpretation of photographs has been done using a positivist paradigm providing evidence for so-called "objective research" (Stasz 1979). Our goal towards anti-oppressive culturally safe research had a social constructionist view to understand the meaning of the photograph from the taker's perspective (e.g., see: Tagg 1988). In addition, we appreciated that the women, the research team, and all other viewers of the pictures would bring their own social position and interests to the interpretation of the photographs. The task for interpretation became as much to understand the individual representations and interpretations as it was an examination of the women's and researchers' position in the social world and how this shapes the viewing of social realities.

When applied to the analysis and dissemination of the women's images of traditional healing practices, identity, or social problems discussed, the culturally safe lens ensures the women are not relabeled as "irresponsible" or "incapable" or as resistant patients (Frideres 1994; 2009). The women put forth this level of complexity and we argue that it then also becomes the responsibility of the researchers and community stakeholders (who may also show the women's pictures) to ensure dissemination of the visual images is placed in the historical and neo-colonial context.

A culturally safe lens ensures the women's visual images on cultural and spiritual healing are presented using their own words and context. This means that the women's perspectives of the importance of these practices are understood as noted above, but also within the backdrop of their historical importance, as well as of wrongdoings, including crimi- nalization of spiritual practices and the implications of mainstream medical bias (see, e.g., Frideres 2009). A culturally safe lens also helps to ensure that these images are presented alongside current calls for restoring traditional practice and Indigenous knowledge towards increasing the health and well-being of current generations (see, e.g., Mitchell and Maracle 2005; Martin-Hill 2009).

Cultural safety applied to Aboriginal identity ensures that while there is a focus on the similarities in the women's experiences, the visual images are viewed with an appreciation for the "differences" among the women. It is well established that $\mathrm{Ab}$ original identity represents a "living entity" adapting to multiple roles representative of generational, locational differences, as well as experiences of the women as members of particular subgroups (e.g., Inuit, Metis, First Nation, Cree, Ojibwa, and the list goes on), gender, and current realities of living in a diverse society (Frideres 2008). While understanding the women's images in a way that realizes the context of colonial domination and how "authentic" nativeness has been typically understood (see, e.g., Monture-Angus 1995; Lawrence 2009), the women's photovoice images must also speak to their multifaceted identities and challenge assumptions about homogeneity.

A culturally safe lens sets the social problems the women discuss (e.g., racism, conditions on-reserve, food security, and poverty) in Aboriginal people's location on the margins of the political economy and their unequal health status. The challenge is to acknowledge the inequalities that the women are attesting to, while using this lens to ensure that their images 
and words are not used to create further difference, culturalism, and Othering. Worst case scenarios have been misused as symbolic of pathological peoples and culture, and attention is taken from wider economic, social, historic, and economic contexts of people's lives. "Culturalism diverts our attention" (Browne and Fiske 2008:10) from "the burden of history" (Browne and Fiske 2008:9) and constructs people as "more different [from "us"] than they really are" (Varcoe and McCormick 2007 as cited in Browne and Fiske 2008:11).

Part of the problem of culturalism is identifying how particular "social problems" become marked as Aboriginal or cultural problems. Previous research on Aboriginal self-government has shown how Aboriginal governors are recognized as governing citizens with specific ill health, usually seen as "urgent moral needs" rather than being viewed as governors of citizens of good health. Non-Aboriginal governors, on the other hand, are not similarly forced to contend with what Aboriginal governors may recognize as urgent needs in non-Aboriginal communities. In other words, "white" governors are "dissociated from discredited subjects" and not contending with health issues directly associated with racialized identities. Aboriginal governors, on the other hand, "are associated with discredited racial subjects as defined by racial ethnic identity" (Fiske and Browne 2006:98). It is in this context that the women's pictures must be understood.

We argue that the photovoice images risk being viewed as stereotypes of Aboriginal peoples and culture, and that the culturally safe lens helps to emphasize an Indigenous voice while putting forward the link to the impact of colonialism and social violence against Aboriginal people.

\section{Conclusion}

This paper discussed the potential of photovoice as an anti-oppressive method, suitable to research with Aboriginal peoples. Findings suggest that photovoice has the potential to develop counter-hegemonic anti-oppressive knowledge, but that this may be lost unless participants, researchers, and stakeholders intentionally and thoughtfully apply a culturally safe anti-oppressive lens.

The photovoice process was shown to facilitate a deepened level of critical consciousness among the VBC participants, as well as provide a balance of power between researchers and participants, uncovering voices not often heard. Other benefits were increased appreciation of cultural understanding, relationship developing among participants, and increased capacity and skills building. However, the photovoice process was not intuitively anti-oppressive. Limitations included the risk that pictures produced may reify mainstream culturalized images. This was evidenced in the women's fear of having social problems, spiritual practices, and identities misunderstood or culturalized. The flip side of the fear of culturalism was that their stories are not shared and research is not done. This was also not a solution the VBC women wanted to consider. Alternatively, only the positive experiences within the health care environment and positive experiences of their health, strength, and resilience would be shared, but the women did not want to miss sharing the worst stories, examples of racism, and examples of continued oppression through colonization and neo-colonialism.

We envision modifying photovoice by including a culturally safe anti-oppressive lens. The stories and pictures of the VBC women must be linked to the effect of colonization and neo-colonialism, recognizing the burden of history: forced assimilation of Aboriginal peoples through appropriating lands, outlawing spiritual and cultural practices, forced indoctrination into dominant culture through residential schools, forced marginalization on-reserves, and continued discrimination and racism. This also includes culturally safe instruction for anyone displaying photovoice findings. An anti-oppressive lens suggests that we must not privilege cultural difference, but name relationships of economic disparities and power relations linked to health and address them.

\section{References}

Adams, Karen et al. 2012. “Use of Participatory Research and Photovoice to Support Urban Aboriginal Healthy Eating." Health and Social Care in the Community 20(5):497-505.

Anderson, Joan M. 2000. “Gender, Race, Poverty, Health, and Discourses of Health Reform in the Context of Globalization: A Postcolonial FeministPerspective in Policy Research." Nursing Inquiry 7:220-229.

Anderson, Joan M. 2004. “The Conundrums of Binary Categories: Critical Inquiry Through the Lens of Postcolonial Feminist Humanism." Canadian Journal of Nursing Research 36(4):11-16.

Anderson, Joan et al. 2003. “'Re-Writing' Cultural Safety Within the Postcolonial/Postnationalist Feminist Project: Toward New Epistemologies of Healing." Advances in Nursing Science 25(3):196-214.

Browne, Annette J. and Jo-Anne Fiske. 2001. "First Nations Women's Encounters With Mainstream Health Care Services." Western Journal of Nursing Research 23(2):126-147.

Browne, Annette and Jo-Anne Fiske. 2008. “The Relevance of Cultural Safety in the Delivery of HIV/AIDS Nursing Care." Powerpoint Presentation, School of Nursing, Uni-
Our findings point to the potential of photovoice to the development of critical consciousness among the participants, and the importance of deliberately situating this process within a culturally safe lens to achieve anti-oppressive outcomes.

\section{Acknowledgements}

The authors want to express appreciation to the women whose words and pictures are shared here and hearten this work. We also want to acknowledge the work and support of the Indigenous Peoples' Health Research Centre.

versity of British Columbia. Retrieved September 10, 2009 (http://www.catie.ca/pdf/CANAC/2007/Browne\%20-\%20Relevance\%20of\%20Cultural\%20Safety.pdf).

Browne, Annette J. Vicki L. Smye, and Colleen Varcoe, 2007. “Postcolonial-Feminist Theoretical Perspectives and Women's Health." Pp. 124-142 in Women's Health in Canada: Critical Perspectives on Theory and Policy, edited by M. Morrow, O. Hankivsky, C. Varcoe: Toronto: University of Toronto Press.

Burke, Dawn and Joan Evans. 2011. "Embracing the Creative The Role of Photo Novella in Qualitative Nursing Research." International Journal of Qualitative Methods 10(2):164-177.

Carlson, Elizabeth. D., Joan Engebretson, and Robert M. Chamberlain. 2006. "Photovoice as a Social Process of Critical Consciousness." Qualitative Health Research 16:836-852.

Castleden, Heather and Theresa Garvin. 2008. "Modifying Photovoice for Community-Based Participatory Indigenous Research." Social Science and Medicine 66(6):1393-1405.

Chonody, Jill et al. 2013. "Violence Through the Eyes of Youth: A Photovoice Exploration." Journal of Community Psychology 41(1):84-101. 
Darias-Beautell, Eva. 2000. Contemporary Theories and Canadian Fiction Shifting Sands. New York: The Edwin Mellen Press.

Fiske, Jo-Anne and Annette Browne. 2006. “Aboriginal Citizen, Discredited Medial Subject: Paradoxical Constructions of Aboriginal Women's Subjectivity in Canadian Health Care Policies." Policy Sciences 39:91-111.

Freedman, Darcy A. et al. 2014. “Using Photovoice to Develop a Grounded Theory of Socio-Environmental Attributes Influencing the Health of Community Environments." British Journal of Social Work 44(5):1301-1321.

Freire, Paulo. 1970. Pedagogy of the Oppressed. New York: Herder and Herder.

Freire, Paulo. 1973. Education for Critical Consciousness. New York: Seabury Press.

Frideres, James S. 1994. “Racism and Health: The Case for Native People." Pp. 202-220 in Health, Illness, and Health Care in Canada, edited by B. S. Bolaria, H. Dickinson. Toronto: Harcourt Brace and Company.

Frideres, James S. 2008. "Aboriginal Identity in the Canadian Context." The Canadian Journal of Native Studies 2:313-342.

Frideres, James S. 2009. “Overcoming Hurdles: Health Care and Aboriginal People." Pp. 183-203 in Health, Illhess, and Health Care in Canada, edited by B. S. Bolaria, H. Dickinson. Toronto: Nelson Education.

Gill, Thomas M. and Alvan R. Feinstein. 1994. "A Critical Appraisal of the Quality of Quality of Life Measurements." Journal of the American Medical Association 272:619-626.

Hill, Patricia Collins. 1998. Black Feminist Thought: Knowledge, Consciousness and the Politics of Empowerment. New York: Routledge.

Hill, Patricia Collins. 2007. "Black Feminist Thought, 1990/2000." Pp. 611-621 in Sociological Theory in the Contemporary Era, edited by S. Appelrouth, L. Desfor Edles. London: Pine Forge Press an Imprint of Sage Publications.

Hill, Patricia Collins. 2012. "Just Another American Story? The First Black First Family." Qualitative Sociology 35(2):123-141.
Hooks, Bell. 1989. Boneblack: Memories of Girhhood. New York: Henry Holt.

Hooks, Bell. 1990. Yearning: Race, Gender, and Cultural Politics. Boston: South End.

Konecki, Krzysztof. 2009. “Teaching Visual Grounded Theory.” Qualitative Sociology Review 5(3):64-92.

Kubicek, Katharina et al. 2012. “Photovoice as a Tool to Adapt an HIV Prevention Intervention for African American Young Men Who Have Sex with Men." Health Promotion Practice 13(4):535-543.

Lai, Shalini, Tal Jarus, and Melinda J. Suto. 2012، “A Scoping Review of the Photovoice Method: Implications for Occupational Therapy Research." Canadian Journal of Occupational Therapy 79(3):181-190.

Lawrence, Bonita. 2009. "Gender, Race, and the Regulation of Native Identity in Canada and the United States: An Overview." Hypatia 18:3-31.

Leedham, Beth and Patricia A. Ganz. 1999. “Psychosocial Concerns and Quality of Life in Breast Cancer Survivors." Cance Investigation 17(5):342-348.

Marrett, Loraine, Carmen R. Jones, and Karen Wishart. 2004. “FirstNations Cancer Research and Surveillance Priorities for Canada: Workshop Report. Cancer Care Ontario." Retrieved August 19, 2008 (https:/ www.cancercare.on.ca/common/pages/UserFile.aspxffileld=13688).

Martin-Hill, Dawn. 2009. “Traditional Medicine in Contemporary Contexts: New Directions." Conference Session at the National Aborigina Health Organization: Our People, Our Health Conference, Ottawa.

Mitchell, Terry L. and Dawn T. Maracle. 2005. "Healing the Generations: Post-Traumatic Stress and the Health Status of Aboriginal Populations in Canada." Journal of Aboriginal Healt 2(1). Retrieved March 19, 2008 (http://www.naho.ca/jah/english/jah02_01/JournalVol2No1ENG4headinggenerations.pdf).

Moffitt, Pertice and Ardene Robinson Vollman. 2004. “Photovoice: Picturing the Health of Aboriginal Women in a Remote Norther Community." Canadian Journal of Nursing Research 36(4):189-201.

Monture-Angus, Patricia. 1995. Thunder in My Soul: A Mohawk Woman Speaks. Halifax: Fernwood Publishing.
Moosa-Mitha, Mehmoona. 2005. “Situating Anti-Oppressive Theories Within Critical and Difference-Centered Perspectives." Pp. 37-72 in Research as Resistance: Critical, Indigenous, and Anti-Oppressive Approaches, edited by L. Brown, S. Strega. Toronto: Canadian Scholars Press.

Nazroo, James Y. and David R. Williams. 2006. “The Social Determination of Ethnic/Racial Inequalities in Health." Pp. 238266 in Social Determinants of Health, edited by M. Marmot, R. G. Wilkinson. Oxford: Oxford University Press.

Okolie, Andrew. 2005. "Toward an Anti-Racist Research Framework: The Case for In-Depth Interviewing." Pp. 241-268 in Critical Issues in Anti-Racist Research Methodologies, edited by G. J. Sefa Dei, G. S. Johal. New York: Peter Lang.

Poudrier, Jennifer and Janice Kennedy. 2007. "Embodiment and the Meaning of the 'Healthy Body': An Exploration of Aboriginal Women's Perspectives of Healthy Body Weight and Body Image." Journal of Aboriginal Health 4(1):15-24.

Razack, Sherene. 1998. Looking White People in the Eye: Gender, Race, and Culture in Courtrooms and Classrooms. Toronto: University of Toronto Press.

Rigney, Lester. 1999. “Internationalization of an Indigenous Anti-Colonial Cultural Critique of Research Methodologies: A Guide to Indigenist Research Methodology and Its Principles." Wicazo SA Journal of Native American Studies Review 14(2):109-121.

Robbins, Julian A. and Jonathan Dewar. 2011.“Traditional Indigenous Approaches to Healing and the Modern Welfare of Traditional Knowledge, Spirituality, and Lands: A Critical Reflection on Practices and Policies Taken From the Canadian Indigenous Example." The International Indigenous Policy Journal 2(4). Retrieved March 19, 2013 (http://irlib.uwo.ca/iipj/vol2/iss4/2).

Schneider, Sebastian. 2008. "Challenging the Cultural Mosaic: Shani Mootoo's 'Out on Main Street."' Current Objectives of Postgraduate American Studies 13(9). Retrieved March 19, 2013 (http:// copas.uni-regensburg.de/article/view/105/129).
Smith, Linda Tuhiwai. 2005. “On Tricky Ground: Researching the Native in the Age of Uncertainty." Pp. 85-107 in The SAGE Handbook of Qualitative Research, edited by N. K. Denzin, Y. S. Lincoln. Beverly Hills, CA: Sage Publications.

Stasz, Clarice. 1979. "The Early History of Visual Sociology." Pp. 119-137 in Images of Information, edited by J. Wagner. Beverly Hills, CA: Sage Publications.

Tagg, John. 1988. The Burden of Representations: Essays on Photographies and Histories. Basingstoke: Macmillan Education.

Waldram, James B., Doris Ann Herring, and T. Kue Young. 2006. Aboriginal Health in Canada: Historical, Cultural, and Epidemiological Perspectives. Toronto, Buffalo, London: University of Toronto Press.

Wang, Caroline. 2003. “Using Photovoice as a Participatory Assessment and Issue Selection Tool: A Case Study With the Homeless in Ann Arbor." Pp. 183-198 in Community Based Participatory Research for Health, edited by M. Minkler, N. Wallerstein. California: Jossey-Bass.

Wang, Caroline and Mary Ann Burris. 1997. "Photovoice: Concept, Methodology, and Use for Participatory Needs Assessment." Health and Behavior 24:369-387.

Wang, Caroline and Yanique A. Redwood-Jones. 2001. "Photovoice Ethics: Perspectives From Flint Photovoice." Health Education and Behaviour 28(5):560-572.

Wang, Caroline, Jennifer Cash, and Lisa Powers. 2000. "Who Knows the Streets as Well as the Homeless? Promoting Personal and Community Action Through Photovoice." Health Promotion Practice 1:81-89.

Wing, Adrien Katherine, (ed.). 2003. Critical Race Feminism: A Reader. New York: New York University Press.

Wood, Pamela and MargaretSchwass.1993. "Cultural Safety: A Framework for Changing Attitudes." Nursing Praxis in New Zealand 8(1):4-15.

Brooks, Carolyn M. and Jennifer Poudrier. 2014. “Anti-Oppressive Visual Methodologies: Critical Appraisal of Cross-Cultural Research Design." Qualitative Sociology Review 10(4):32-51. Retrieved Month, Year (http://www.qualitativesociologyreview.org/ENG/archive_eng.php). 